\title{
Leukocyte Trafficking Induction
}

National Cancer Institute

\section{Source}

National Cancer Institute. Leukocyte Trafficking Induction. NCI Thesaurus. Code C40754.

Leukocyte Trafficking Induction involves initiation of circulation of white blood cells from the blood stream to tissues or secondary lymphoid organs, to the lymphatics, and back to the bloodstream via the thoracic duct. 